\title{
Avaliação da suscetibilidade à varicela no paciente pediátrico portador de insuficiência renal crônica
}

\author{
Evaluation of chickenpox susceptibility in children with chronic renal failure
}

\author{
Evandro Roberto Baldacci ${ }^{1}$, Simone Nascimento Fagundes ${ }^{2}$, Vera Hermina K. Koch ${ }^{3}$
}

\section{RESUMO}

Objetivo: Avaliar a suscetibilidade natural à varicela de crianças e adolescentes portadores de insuficiência renal crônica (IRC).

Métodos: Estudo transversal de 83 pacientes com idade acima de 18 meses e inferior a 18 anos, durante 2000 e 2001, com ritmo de filtração glomerular (RFG) abaixo de $70 \mathrm{~mL} / \mathrm{min} / 1,73 \mathrm{~m}^{2}$, portando cartão vacinal preconizado pela Fundação Nacional de Saúde e que não receberam nenhuma dose da vacina específica. Do total, três pacientes (3/83) foram excluídos, por terem recebido doses da vacina por meio de órgãos não governamentais. A sorologia foi realizada pelo método Enzyme-Linked Immuno Sorbent Assay, considerando-se títulos sorológicos protetores acima de $100 \mathrm{mUA} / \mathrm{mL}$.

Resultados: Os pacientes renais crônicos tinham idade mediana de 11 anos, 66\% eram masculinos, 60\% procedentes do próprio município de São Paulo, com RFG médio de $33,6 \mathrm{~mL} / \mathrm{min} / 1,73 \mathrm{~m}^{2}$. O diagnóstico clínico de varicela por profissional médico ocorreu em 39 pacientes; destes, 10\% se mostraram soronegativos. Dos 80 pacientes restantes, $21(26 \%)$ apresentaram títulos não protetores para varicela. A prevalência de suscetibilidade em menores de seis anos foi 7,93 (IC95\%=3,29-19,12) vezes superior à de maiores de seis anos.

Conclusões: Houve diminuição da suscetibilidade à varicela com a idade. Pacientes abaixo de seis anos foram cerca de oito vezes mais suscetíveis à varicela que os renais crônicos com idade mais avançada e duas vezes mais suscetíveis do que a população pediátrica brasileira de mesma idade.

Palavras-chave: vacinação; insuficiência renal crônica; criança; adolescente; varicela.

\section{ABSTRACT}

Objective: To evaluate the immune response to chickenpox natural infection in pediatric patients with chronic renal insufficiency.

Methods: This cross-sectional study enrolled 83 patients between 18 months and 18 years old, with glomerular filtration rate below $70 \mathrm{~mL} / \mathrm{min} / 1.73 \mathrm{~m}^{2}$, during the years 2000 and 2001, who did not received specific immunization according to official documentation. Three patients (3/83) had been previously vaccinated by non-governmental agencies and were excluded. Varicella antibodies were evaluated by Enzyme-Linked Immuno Sorbent Assay and antibody titers above $100 \mathrm{mUA} / \mathrm{mL}$ were considered protective.

Results: The median age was 11 years old, 66\% were male, $60 \%$ lived in the city of São Paulo, with an average glomerular filtration rate of $33.6 \mathrm{~mL} / \mathrm{min} / 1.73 \mathrm{~m}^{2}$. Clinical diagnosis of chickenpox was done by pediatricians in 39 patients and four of these 39 were seronegative for varicella. Susceptibility to chickenpox was found in $21 / 80(26 \%)$ patients and the relative prevalence of susceptibility to the disease was $7.93(95 \% \mathrm{CI}=3.29-19.12)$ higher in patients under six years of age.

Conclusions: Susceptibility to varicella infection decreased with age. Patients younger than six years were eight times more susceptible than older patients and twice more susceptible compared to the Brazilian pediatric population of the same age group.

Key-words: vaccination; renal insufficiency, chronic; child; adolescent; chickenpox.
1Professor livre-docente da Unidade de Infectologia Pediátrica do Instituto da Criança do Hospital das Clínicas da Faculdade de Medicina da Universidade de São Paulo (ICr/HC-FMUSP), São Paulo, SP, Brasil

${ }^{2}$ Mestre e médica pesquisadora da Unidade de Nefrologia Pediátrica do ICr/HC-FMUSP, São Paulo, SP, Brasil

${ }^{3}$ Doutora e médica responsável pela Unidade de Nefrologia Pediátrica do ICr/HC-FMUSP, São Paulo, SP, Brasil

\section{Rua Giovani Patolli, 606/12, torre 4 CEP 03227-090 \\ E-mail: sifagun@terra.com.br}

Fonte financiadora: Coordenação de Aperfeiçoamento de Pessoal de Nível Superior (Capes), com bolsa de mestrado concedida a Simone Nascimento Fagundes 


\section{Introdução}

Apesar do estabelecimento de rotinas para controle, as infecções virais e bacterianas continuam sendo a maior causa de morbidade e mortalidade nos pacientes com insuficiência renal crônica (IRC) - principalmente naqueles em terapia substitutiva ${ }^{(1)}$. As infecções contribuem com 30 a $36 \%$ das mortes dos pacientes em diálise; entretanto, muitas destas mortes poderiam ser prevenidas por vacinas ${ }^{(1)}$.

A aplicação de vacinas possui um importante papel na atenuação do risco de infecções preveníveis em portadores de IRC. Entretanto, nestes pacientes, a resposta imune à vacinação é limitada, com taxa potencialmente insuficiente de soroconversão pós-vacinação, resultando em baixos títulos de anticorpos ou manutenção de títulos soroprotetores por tempo reduzido ${ }^{(1,2)}$. A resposta insuficiente à vacinação pode ser atenuada por meio da elevação da dose das vacinas e/ou do aumento no número de doses ${ }^{(1,2)}$.

O perfil de gravidade clínica da varicela nos pacientes em tratamento conservador e em terapia dialítica normalmente não difere do verificado em pessoas imunologicamente $\operatorname{sadias}^{(1-3)}$. $\mathrm{O}$ mesmo não ocorre em pacientes transplantados em uso de medicações imunossupressoras, que apresentam alta morbimortalidade frente a esta infecção ${ }^{(4,5)}$. A vacinação para varicela no grupo de pacientes com IRC, no Brasil, não é realizada segundo calendário vacinal básico preconizado pela Fundação Nacional de Saúde (Funasa) ${ }^{(5-8)}$. Embora o Brasil já tenha licenciado a vacina de varicela, esta ainda não faz parte do calendário vacinal do Ministério da Saúde devido ao alto custo ${ }^{(5-8)}$. A Sociedade Brasileira de Pediatria (SBP) preconiza a utilização da vacina conforme rotina americana ${ }^{(9,10)}$. Pacientes imunocomprometidos no Brasil, incluindo os renais crônicos em estágio de pré-transplante, podem receber a vacina nos Centros de Referência de Imunobiológicos Especiais (CRIEs) das Secretarias de Saúde dos Estados ${ }^{(7-12)}$.

A varicela no paciente renal crônico e, mais ainda, no transplantado em uso de imunossupressor evolui com resultados potencialmente fatais ${ }^{(1-9)}$. Estudos que mostram maior susceptibilidade à varicela nestes pacientes reforçam a necessidade de ênfase na avaliação sorológica de títulos protetores e vacinação prévia ao transplante renal. Neste contexto, o objetivo do presente estudo foi avaliar a suscetibilidade natural à varicela de crianças e adolescentes portadores de IRC.

\section{Métodos}

Tratou-se de um estudo transversal dos pacientes portadores de IRC em acompanhamento clínico e ambulatorial da Unidade de Nefrologia Pediátrica do Instituto da Criança do Hospital das Clínicas da Faculdade de Medicina da Universidade de São Paulo (ICr/HC-FMUSP), no período compreendido entre janeiro de 2000 e dezembro de 2001. O trabalho contou com consulta a prontuários de pacientes, preenchimento de questionário padronizado, análise de cartão de vacinação e avaliação sorológica e obteve aprovação prévia da Comissão de Ética do ICr/FMUSP e do HC-FMUSP.

Os critérios de inclusão no estudo foram: ritmo de filtração glomerular (RFG) abaixo de $70 \mathrm{~mL} / \mathrm{min} / 1,73 \mathrm{~m}^{2}$, idade igual ou superior a 18 meses e inferior a 18 anos e cartão de vacina brasileiro no momento da entrevista ${ }^{(5)}$, além de assinatura de consentimento informado por responsável legal. Considerou-se critério de exclusão para avaliação de suscetibilidade natural a exposição a alguma dose da vacina contra varicela.

Utilizou-se a fórmula de Schwartz ${ }^{(13)}$ para calculo do RFG dos pacientes incluídos, adotando-se, para análise estatística, três faixas: $51-70,21-50$ e $\leq 20 \mathrm{~mL} / \mathrm{min} / 1,73 \mathrm{~m}^{2}$.

O limite inferior de idade de 18 meses foi adotado, pois, nesta faixa etária, as crianças brasileiras já completaram o esquema vacinal básico ${ }^{(5,9-12)}$ proposto pelo Ministério da Saúde. Quanto ao limite superior, levou-se em conta a idade a partir da qual começa a transferência de pacientes do ICr para as Unidades de Nefrologia para adultos.

Procedeu-se à entrevista por questionário estruturado, respondido pelos pacientes, pais e/ou responsáveis. O questionário versou sobre idade, sexo, tempo de seguimento no serviço, procedência atual, etiologia da IRC, tipo de terapia de suporte renal, doenças associadas, antecedentes mórbidos do paciente, avaliação do grau de escolaridade dos pais/responsáveis, situação econômica da família e diagnóstico clínico por profissional médico de varicela. Seqüencialmente, os dados foram complementados com análise de prontuário e avaliação clínica durante consulta ambulatorial e/ou internação.

Após consentimento informado e assinado pelos pais ou responsáveis, procedeu-se à coleta de sangue para avaliação sorológica para varicela. $\mathrm{O}$ material recolhido fez parte da coleta de sangue da avaliação rotineira dos pacientes envolvidos no estudo e foi encaminhado ao Laboratório de Virologia do Instituto de Medicina Tropical de São Paulo da FMUSP. A titulação de anticorpos foi realizada por meio de técnica do Enzyme-Linked Immuno Sorbent Assay (ELISA), 
sendo considerado título protetor contra a doença o valor igual ou acima de $100 \mathrm{mUA} / \mathrm{mL}^{(14,15)}$.

A análise estatística da situação vacinal em relação ao esquema da vacina contra varicela recomendado pela Funasa foi medida em proporções. A prevalência de anticorpos contra o vírus da varicela entre os vacinados sem história clínica da doença foi apresentada em proporções. Após dicotomizar as variáveis contínuas na mediana, possíveis associações com aspectos demográficos, socioeconômicos e clínicos foram verificadas por cálculo de prevalências e prevalências relativas, com os respectivos intervalos de $95 \%$ de confiança. O teste do qui-quadrado simples e para tendência e, quando pertinente, o teste exato de Fisher foram aplicados para avaliar diferenças entre proporções. Para todas as comparações, o nível de significância estatística foi estabelecido em $p<0,05$.

\section{Resultados}

O estudo realizado foi do tipo descritivo (retrospectivo e prospectivo) de uma população de 120 crianças portadoras de IRC. Neste estudo, foram incluídas 83 crianças com IRC de etiologia variada, sendo 55 (66\%) do sexo masculino, ativos no ambulatório e enfermaria da Unidade de Nefrologia Pediátrica do ICr/HC-FMUSP, com idade mediana de 11 anos (variação interquartil de 5,5 a 14 anos). O tempo de seguimento dos pacientes, desde o momento da admissão no serviço, foi, em média, de 44,5 meses. Do total de pacientes, $60 \%$ eram provenientes da própria cidade de São Paulo. O grau de escolaridade médio foi de 7 anos para os pais e para as mães. No ano de 2000, a renda per capita média foi $\mathrm{R} \$ 191,60$.

A etiologia da IRC nos pacientes incluídos mostrouse assim distribuída: 17 casos (20\%) de glomerulopatias (8\% glomeruloesclerose segmentar e focal, $5 \%$ esclerose mesangial difusa, $4 \%$ glomerulopatia crônica, $4 \%$ outras) e 58 casos $(70 \%)$ de malformações do aparelho gênito-urinário (51\% com uropatias obstrutivas, $14 \%$ com hipodisplasias renais e $7 \%$ com agenesia renal). O terceiro grupo apresentou oito pacientes $(10 \%)$ com outros tipos de patologias renais (4\% doença policística renal, $4 \%$ tubulopatias, $1 \%$ nefronoftise, $1 \%$ insuficiência renal aguda cronificada).

O estudo avaliou 52 pacientes (63\%) em tratamento conservador, 17 pacientes (20\%) em hemodiálise e 14 pacientes (17\%) em diálise peritoneal. Para aqueles em tratamento conservador, o RFG mediano foi $46,9 \mathrm{~mL} / \mathrm{min} / 1,73 \mathrm{~m}^{2}$ (variação de 10,8 a $69,8 \mathrm{~mL} / \mathrm{min} / 1,73 \mathrm{~m}^{2}$ ). Aqueles com RFG abaixo ou igual a $20 \mathrm{~mL} / \mathrm{min} / 1,73 \mathrm{~m}^{2}$ totalizaram $34 / 83$ pacientes $(41 \%)$.
Somente seis pacientes (7\%) fizeram uso prévio de imunossupressão por tempo médio de 4 anos (mediana: 5 anos; variação: de 1-6 anos). A utilização de imunossupressores ocorreu em média 7,8 anos (mediana: 8 anos; variação: de 1-12 anos) antes da coleta de sorologias do estudo. Dois pacientes $(2,4 \%)$, ambos glomerulopatas, não souberam informar a respeito do uso de imunossupressão previamente ao acompanhamento em nosso serviço. Daqueles que utilizaram imunossupressores, cinco o fizeram após imunização básica; um paciente portador de síndrome nefrótica congênita utilizou corticóide no primeiro ano de vida por curto período e só recebeu doses vacinais posteriormente.

Destaca-se que a exposição à vacina contra varicela monovalente, viabilizada por órgãos não governamentais, ocorreu em três $(3,6 \%)$ crianças. A análise da relação entre exposição vacinal e renda per capita ou escolaridade dos pais não obteve significância estatística devido à baixa cobertura vacinal dos pacientes do estudo. Ressalta-se que estes três pacientes foram excluídos da análise de suscetibilidade natural, objetivo primordial do trabalho, mas foram avaliados após consentimento informado, em relação aos títulos de anticorpos contra varicela e soroproteção.

Dos 80 pacientes não previamente vacinados, 21 (26\%) apresentaram títulos não protetores para varicela. A ocorrência de varicela com diagnóstico clínico por profissional médico nesta população renal crônica ocorreu em 47\% (39/80), sendo que quatro dos $39(10 \%)$ pacientes com história prévia de varicela mostraram-se soronegativos.

A suscetibilidade à varicela, definida por título de anticorpo $<100 \mathrm{mUA} / \mathrm{mL}$, diminuiu com a idade $(p<0,00001)$. A probabilidade do paciente renal crônico com idade até seis anos ser suscetível à varicela mostrou prevalência relativa de 7,93 (IC95\% = 3,29-19,12) $(p<0,001$, Tabela 1$)$, em comparação aos de idade mais avançada.

Foram avaliados fatores que poderiam estar associados a títulos não protetores de anticorpos contra varicela por

Tabela 1 - Distribuição de prevalência de suscetibilidade à varicela dos 80 pacientes classificados por faixa etária

\begin{tabular}{lc}
\hline $\begin{array}{l}\text { Idade dos pacientes com } \\
\text { títulos não protetores }\end{array}$ & $\begin{array}{c}\text { Número de } \\
\text { pacientes/total (\%) }\end{array}$ \\
\hline Até 5 anos & $14 / 19(73,7)$ \\
$6-9$ anos & $3 / 19(15,8)$ \\
$10-13$ anos & $2 / 19(10,5)$ \\
13 ou mais anos & $2 / 23(8,7)$ \\
\hline
\end{tabular}

Qui-quadrado para tendência: $p=0,00001$ 
ocasião da inclusão na pesquisa (Tabelas 2 e 3). Os valores denominados taxas de prevalência de suscetíveis, conforme as Tabelas 2 e 3, devem ser interpretados como indicativos de associação. As variáveis estudadas: sexo, procedência, renda per capita familiar, escolaridade materna e paterna, etiologia da IRC, imunossupressão, RFG, tipo de terapia da IRC, escore $Z$ do peso e da estatura para idade e do peso para estatura, quando avaliadas do ponto de vista estatístico, não apresentaram significância na análise de susceptibilidade à varicela. $\mathrm{O}$ antecedente clínico de varicela mostrou relação com menor susceptibilidade à varicela $(p<0,003)$.

\section{Discussão}

Estudos para avaliar a imunogenicidade de vacinas em crianças e adolescentes portadores de IRC têm contribuído para caracterizar a deficiência imunológica destes pacientes.
A ineficácia da resposta vacinal do portador de uremia está associada a um efeito direto das toxinas urêmicas ou à ação indireta das intervenções terapêuticas no sistema imune celular e humoral. Alterações imunológicas associadas à uremia podem determinar respostas insuficientes e menos duradouras em relação à população normal. Sugere-se que a base do defeito imunológico na IRC seja a inadequação da função co-estimulatória da célula apresentadora de antígeno, por expressão insuficiente da molécula B7-2 (CD86) em monócitos, com conseqüente ativação insuficiente do linfócito efetor. Esta deficiência pode ser recuperada por terapêutica substitutiva renal de boa qualidade ${ }^{(16-19)}$.

Outro marcador de mau prognóstico em pacientes com IRC terminal, a interleucina 6 (IL-6), também exerce seus maiores efeitos por via sistêmica, por meio da circulação sanguínea. Evoluem para a instalação de falência do sistema imune, quando a ativação se efetua cronicamente. Este estado

Tabela 2 - Distribuição dos 80 pacientes quanto a fatores demográficos e nutricionais, possivelmente associados a título não protetor de anticorpos contra varicela

\begin{tabular}{|c|c|c|c|}
\hline Variável & $\begin{array}{c}\text { Número de } \\
\text { pacientes/total (\%) }\end{array}$ & $\begin{array}{c}\text { Prevalência relativa } \\
\text { (IC95\%) }\end{array}$ & $\begin{array}{c}\text { Valor de } \\
p\end{array}$ \\
\hline Sexo & & & 0,45 \\
\hline Masculino & $12 / 53(22,6)$ & $0,68(0,33-1,41)$ & \\
\hline Feminino & $9 / 27(33,4)$ & 1,00 & \\
\hline Procedência & & & 0,93 \\
\hline Cidade de São Paulo & $12 / 47(25,5)$ & $0,94(0,45-1,96)$ & \\
\hline Interior de São Paulo/Outros Estados & $9 / 33(27,3)$ & 1,00 & \\
\hline Escolaridade materna" & & & 0,45 \\
\hline Até 7 anos & $14 / 43(32,5)$ & $1,49(0,68-3,26)$ & \\
\hline$>7$ anos & $7 / 32(21,8)$ & 1,00 & \\
\hline Escolaridade paterna ${ }^{\#}$ & & & 0,99 \\
\hline Até 7 anos & $12 / 44(27,3)$ & $0,99(0,46-2,12)$ & \\
\hline$>7$ anos & $8 / 29(27,6)$ & 1,00 & \\
\hline Renda per capita em 2000 & & & 0,52 \\
\hline Até $\mathrm{R} \$ 105,0$ & $12 / 39(30,3)$ & $1,40(0,67-2,95)$ & \\
\hline$>\mathrm{R} \$ 105,0$ & $9 / 41(21,9)$ & 1,00 & \\
\hline Antecedente clínico de varicela & & & 0,003 \\
\hline Sim & $4 / 39(10,3)$ & $0,25(0,09-0,67)$ & \\
\hline Não & $17 / 41(41,4)$ & 1,00 & \\
\hline Escore Z estatura/idade & & & 0,20 \\
\hline Até $-2 \mathrm{dp}$ & $8 / 42(19,0)$ & $0,56(0,26-1,19)$ & \\
\hline$>-2 d p$ & $13 / 38(34,2)$ & 1,00 & \\
\hline Escore Z peso/idade & & & 0,84 \\
\hline Até $-2 \mathrm{dp}$ & $7 / 30(23,4)$ & $0,83(0,38-1,83)$ & \\
\hline$>-2 d p$ & $14 / 50(28,0)$ & 1,00 & \\
\hline Escore Z peso/altura\# & & & 0,16 \\
\hline Até - $2 d p$ & $1 / 12(8,3)$ & $0,28(0,04-1,86)$ & \\
\hline$>-2 d p$ & $20 / 66(30,3)$ & 1,00 & \\
\hline
\end{tabular}

${ }^{\#} \mathrm{n}$ total $<80$ por informação ausente 
de exacerbação inflamatória, denominado de pré-ativação, se correlaciona com uma resposta insuficiente à vacinação contra hepatite $\mathrm{B}$ e demonstra que, quanto maior a ativação de citocinas pró-inflamatórias, pior é a ativação do linfócito $T^{(16,19)}$. Entretanto, apesar do potencial para resposta inadequada à vacinação devido a esta falência do sistema imune, as vacinas têm papel importante para atenuar o risco de infecção do renal crônico ${ }^{(20-23)}$.

Este trabalho se classifica como estudo de prevalência, em que tanto a exposição quanto o efeito são verificados simultaneamente. Assim, resultados para possíveis variáveis explicativas não levam em conta o tempo prévio à exposição viral natural ou artificial (vacinal), mas o tempo total de vida transcorrido até o dia da entrevista e coleta de sangue para exame. Há escassez de dados na literatura quanto à dosagem de títulos de anticorpos para varicela no renal crônico. A eficácia vacinal, por outro lado, é alvo de interesse, verificando-se a necessidade de realizar sorologia periódica dos pacientes em questão, particularmente antes do transplante renal ${ }^{(4,24)}$.

O presente estudo verificou presença de títulos não protetores em $26 \%$ dos pacientes que não haviam recebido nenhu- ma dose da vacina contra varicela. Por outro lado, apesar do objetivo primordial da pesquisa ter sido a avaliação sorológica da exposição natural ao vírus varicela-zóster, observou-se que três pacientes receberam vacina contra varicela por órgãos não governamentais. Estes não apresentavam história clínica prévia de doença e houve eficácia vacinal em dois deles. Apesar da baixa renda per capita das famílias dos pacientes analisados, não se observou influência da mesma, bem como da escolaridade dos pais, na adesão à vacinação.

Dentre os estudos de levantamento vacinal, realizados em centros internacionalmente reconhecidos de nefrologia pediátrica, destaca-se o de Furth et al. Os autores avaliaram 76/123 (62\%) centros de Nefrologia Pediátrica participantes do North American Pediatric Renal Transplant Cooperative Study (NAPRTCS) e verificaram que 90\% deles recomendam a imunização básica (contra tétano-pertussisdifteria, pólio oral ou inativada, Haemophilus influenzae, hepatite B e sarampo-caxumba-rubéola) para os pacientes pediátricos em diálise e em tratamento conservador. Os autores enfatizam a importância da utilização das vacinas contra varicela, influenza e pneumococo e a boa adesão dos

Tabela 3 - Distribuição dos 80 pacientes quanto a fatores da doença renal, possivelmente associados a título não protetor de anticorpos contra varicela

\begin{tabular}{|c|c|c|c|}
\hline Variável & $\begin{array}{c}\text { Número de } \\
\text { pacientes/total (\%) }\end{array}$ & $\begin{array}{l}\text { Prevalência relativa } \\
\text { (IC 95\%) }\end{array}$ & $\begin{array}{l}\text { Valor de } \\
\qquad p\end{array}$ \\
\hline Etiologia da IRC & & & 0,12 \\
\hline Malformações do aparelho urinário & $15 / 55(27,3)$ & $2,32(0,59-9,14)$ & \\
\hline Outras patologias renais & $4 / 8(50,0)$ & $4,25(0,97-18,57)$ & \\
\hline Glomerulopatias & $2 / 17(11,7)$ & 1,00 & \\
\hline RFG & & & $<0,001$ \\
\hline $51-70 \mathrm{~mL} / \mathrm{min} / 1,73 \mathrm{~m}^{2}$ & $4 / 22(18,2)$ & $2,00(0,65-9,76)$ & \\
\hline $21-50 \mathrm{~mL} / \mathrm{min} / 1,73 \mathrm{~m}^{2}$ & $14 / 25(56,0)$ & $6,16(1,98-19,1)$ & \\
\hline$<20 \mathrm{~mL} / \mathrm{min} / 1,73 \mathrm{~m}^{2}$ & $3 / 33(9,1)$ & 1,00 & \\
\hline Tipo de terapia da IRC & & & 0,31 \\
\hline Conservador & $16 / 51(31,4)$ & $2,51(0,65-9,76)$ & \\
\hline Diálise peritoneal & $3 / 13(23,1)$ & $1,85(0,36-9,45)$ & \\
\hline Hemodiálise & $2 / 16(12,5)$ & 1,00 & \\
\hline Terapia em geral & & & 0,26 \\
\hline Conservador & $16 / 51(31,4)$ & $1,82(0,74-4,45)$ & \\
\hline Terapia substitutiva & $5 / 29(17,2)$ & 1,00 & \\
\hline Imunossupressão & & & 0,66 \\
\hline Nunca usaram & $19 / 72(26,4)$ & $0,79(0,24-2,62)$ & \\
\hline Fez uso em algum momento & $2 / 6(33,4)$ & 1,00 & \\
\hline
\end{tabular}


doentes a esta prática. As vacinas de vírus vivos atenuados devem ser evitadas em transplantados ${ }^{(25)}$.

Laube et al estudaram 62 crianças renais crônicas em diálise e pós-transplantadas, com 13 anos de seguimento, avaliando a taxa de cobertura vacinal de acordo com o calendário sugerido pelo Sistema de Saúde da Suíça. As vacinas preconizadas para todos os pacientes foram contra tétano-pertussis-difteria, pólio, Haemophilus influenzae, hepatite $\mathrm{B}$ e sarampo-caxumba-rubéola; para grupos especiais, incluíram hepatite $A$, varicela, influenza, pneumococo. A cobertura vacinal do esquema básico completo foi $100 \%$ e a cobertura para vacinas especiais também foi $100 \%$, para aqueles com indicação de recebê-las ${ }^{(26)}$.

$\mathrm{O}$ antecedente clínico de varicela apresentou associação com menor suscetibilidade à varicela $(p<0,003)$, demonstrando que o diagnóstico clínico da doença foi feito com competência. Por outro lado, em conformidade com a literatura $^{(20,27-30)}$, realizar a sorologia antes de indicar a vacina é de extrema importância, mesmo em casos com diagnóstico clínico prévio da doença, pois, como demonstra esta casuística, quatro dos 39 pacientes com história prévia de varicela mostraram-se soronegativos para varicela.

A possibilidade de suscetibilidade à varicela verificada em pacientes vacinados e em pacientes com história prévia de varicela clinicamente manifesta, com confirmação diagnóstica por profissional da área médica, enfatiza a importância da avaliação sorológica seriada neste grupo de pacientes, em especial na fase pré-transplante, independentemente da exposição anterior à vacina ou de manifestação clínica compatível com a doença.

O estudo mostra a presença de títulos protetores para varicela em idades mais avançadas, fruto de exposição natural ao vírus. Observa-se que ocorre diminuição progressiva da suscetibilidade, à medida que aumenta a idade do paciente. A suscetibilidade à varicela até a idade de seis anos é cerca de oito vezes maior do que acima desta idade. Realizando uma comparação com o estudo de Yu et al, em 2000, observa-se que a prevalência de suscetibilidade à varicela é cerca de duas vezes maior nas crianças renais crônicas de até seis anos de idade $(p<0,001)$, comparada à de crianças da população brasileira ${ }^{(14)}$. Observa-se queda lenta dos títulos de anticorpos até a idade de 11 anos, semelhante àquela dos indivíduos imunocompetentes.

Em conclusão, a idade mostrou ser o fator de maior importância para a suscetibilidade do paciente renal crônico pediátrico à varicela, independentemente das condições clínicas e imunológicas no momento em que se iniciou a coleta dos dados. Entretanto, é com preocupação que reportamos a alta taxa de títulos não protetores para varicela. $O$ fato observado confirma o risco de morbidade e mortalidade por uma doença imunoprevenível. São necessários esforços para efetuar sorologias periódicas e para garantir a disponibilidade da vacina contra varicela no paciente renal crônico pediátrico, em especial naqueles em preparo para o transplante renal.

\section{Agradecimentos}

À professora doutora Vanda Akeda e à doutora Alexandra Dias Reis, pela realização das sorologias no setor de Virologia do Instituto de Medicina Tropical. Ao professor doutor Crésio Romeu Andrade, pela ajuda valiosa no preparo da análise estatística. Às doutoras Simone Vieira, Andréa Watanabe e Daniele Dias Brum, pelo auxílio na coleta de dados. 


\section{Referências bibliográficas}

1. Rangel MC, Coronado VG, Euler GL, Strikas RA. Vaccine recommendations for patients on chronic dialysis. The Advisory Committee on Immunization Practices and the American Academy of Pediatrics. Semin Dial 2000;13:101-7.

2. Bouchaud $O$. Vaccinations in immunosuppressed patients. Ann Med Interne (Paris) 1997;148:272-9.

3. Gershon AA, Mervish N, LaRussa P, Steinberg S, Lo SH, Hodes D et al . Varicella-zoster virus infection in children with underlying human immunodeficiency virus infection. J Infect Dis 1997;176:1496-500.

4. Neu AM, Fivush BA. Recommended immunization practices for pediatric renal transplant recipients. Pediatr Transplant 1998;2:263-9.

5. Brasil - Ministério da Saúde - Funasa [homepage on the Internet]. Imunizações: calendário básico de vacinação [cited 2003 Dec 01]. Available from: http://www.vacinaonline.fmb.unesp.br/docs/norma\%20de\%20vac.ms.pdf

6. Brasil - Ministério da Saúde - Funasa [homepage on the Internet]. Imunizações: cobertura São Paulo [cited 2003 Dec 01]. Available from: http://tabnet. datasus.gov.br/cgi/tabcgi.exe?pni/CNV/CPNISP.def

7. Ministério da Saúde - Funasa. Manual dos centros de referência de imunobiológicos especiais. Brasília: Ministério da Saúde; 2001.

8. Centro de Vigilância Epidemiológica Prof. Alexandre Vranjac (CVE). Secretaria de Estado da Saúde. Divisão de Imunização. Informe técnico - varicela/2003. São Paulo: Secretaria de Estado da Saúde; 2003.

9. Weckx LY, Carvalho ES. Calendário vacinal: dinâmica e atualização. J Pediatr (Rio J) 1999;75 (Suppl 1):S149-54.

10. Academy American Pediatrics/Centers for Disease Control and Prevention. 2000 Immunization Registry Annual Report [cited 2003 Dec 02]. Available from: http://www.cdc.gov/vaccines/stats-surv/imz-coverage.htm\#chart

11. Centro de Vigilância Epidemiológica Prof. Alexandre Vranjac (CVE). Secretaria de Estado da Saúde. Divisão de Imunização. Imunização: nota de resolução - novo calendário de vacinação para crianças. Diário Oficial do Estado 2002 Dez 02. p. 38.

12. Brasil - Ministério da Saúde - Funasa [homepage on the Internet]. Cobertura vacinal no primeiro ano de vida [cited 2003 Dec 02]. Available from: http://tabnet.datasus.gov.br/cgi/idb2000/cober.htm

13. Schwartz GJ, Brion LP, Spitzer A. The use of plasma creatinine concentration for estimating glomerular filtration rate in infants, children, and adolescents. Pediatr Clin North Am 1987;34:571-90.

14. Yu ALF, Costa JM, Amaku M, Pannuti CS, Souza VAUF, Zanetta DMT et al. Three year seroepidemiological study of varicella-zoster virus in São Paulo, Brazil. Rev Inst Med Trop S Paulo 2000;42:125-8.
15. Reis AD, Pannuti CS, Souza VA. Prevalência de anticorpos para o vírus da varicela-zoster em adultos jovens de diferentes regiões climáticas brasileiras. Rev Soc Bras Med Trop 2003;36:317-20.

16. Girndt M, Sester M, Sester U, Kaul H, Köhler H. Molecular aspects of T- and B-cell function in uremia. Kidney Int Suppl 2001;78:S206-11.

17. Ada G. Vaccines and vaccination. N Engl J Med 2001;345:1042-53.

18. Ensari C, Ekim M, Ikinciogullari A, Tümer N, Ensari A. Are uraemic children immunologically compromised? Nephron 2001;88:379-81.

19. Pecoits-Filho $R$, Bárány $P$, Lindholm $B$, Heimbürger $O$, Stenvinkel $P$. Interleukin- 6 is an independent predictor of mortality in patients starting dialysis treatment. Nephrol Dial Transplant 2002;17:1684-8.

20. Broyer M, Boudailliez B. Varicella vaccine in children with chronic renal insufficiency. Postgrad Med J 1985;61 (Suppl 4):103-6.

21. Neu AM, Fivush BA. Recommended immunization practices for pediatric renal transplant recipients. Pediatr Transplant 1998;2:263-9.

22. Rangel MC, Coronado VG, Euler GL, Strikas RA. Vaccine recommendations for patients on chronic dialysis. The Advisory Committee on Immunization Practices and the American Academy of Pediatrics. Semin Dial 2003;13:101-7.

23. Bourel M, Ardaillou R. Prevention and screening of chronic renal failure. Bull Acad Natl Med 2004;188:1455-68.

24. Fadrowski JJ, Furth SL. Varicella zoster virus: vaccination and implications in children with renal failure. Expert Rev Vaccines 2004;3:291-8.

25. Furth SL, Neu AM, Sullivan EK, Gensler G, Tejani A, Fivush BA. Immunization practices in children with renal disease: report of the North American Pediatric Renal Transplant Cooperative Study. Pediatr Nephrol 1997;11:443-6.

26. Laube GF, Berger C, Goetschel P, Leumann E, Neuhaus TJ. Immunization in children with chronic renal failure. Pediatr Nephrol 2002;17:638-42.

27. Webb NJ, Fitzpatrick MM, Hughes DA, Brocklebank TJ, Judd BA, Lewis MA et al. Immunisation against varicella in end stage and pre-end stage renal failure. Trans-Pennine Paediatric Nephrology Study Group. Arch Dis Child 2000;82:141-3.

28. Furth SL, Fivush BA. Varicella vaccination in pediatric kidney transplant candidates. Pediatr Transplant 2002;6:97-100.

29. Furth SL, Hogg RJ, Tarver J, Moulton LH, Chan C, Fivush BA; Southwest Pediatric Nephrology Study Group. Varicella vaccination in children with renal failure: a report of Southwest Pediatric Nephrology Study Group. Pediatr Nephrol 2003;18:33-8.

30. Prelog M, Pohl M, Ermisch B, Fuchshuber A, Huzly D, Jungraithmayr T et al. Demand for evaluation of vaccination antibody titers in children considered for renal transplantation. Pediatr Transplant 2007;11:73-6. 